\title{
Global health: current issues, future trends and foreign policy
}

\author{
Daniela Kirwan
}

\section{Introduction}

With increasing global connectivity, the impact of an event travels across today's world with the speed of a broadband internet connection. The relevance of national borders is dwindling, and people and determinants of health flow freely in every direction. It is no longer possible to address healthcare in the UK without taking a global view.

This timely conference followed a series of publications including Lord Crisp's Global health partnerships and Sir Liam Donaldson's Health is global: proposals for a government-wide strategy. ${ }^{1,2}$ The ambitious programme drew together a range of key players in global health who addressed many challenges facing those working in the field, and proposed positive measures to take old and new collaborations forward.

The conference was energetic and facilitated networking and sharing of ideas between politicians, policy makers and clinicians. The eminence of the speakers and enthusiasm of the delegates highlighted the abundance of expertise, political will, and sheer number of healthcare professionals with an interest in global health.

\section{The changing context: epidemiology and public health challenges}

Although changes in health indicators have been favourable overall, distribution of gains has been unequal. Despite a global decline in population numbers and density, there is rapid growth in areas of Asia, and severe exceptions in life expectancy improvements exist; for example, the HIV/AIDS pandemic has contributed to the reversal of previous advances in Zimbabwe, where life expectancy at birth is currently only 40.9 years. $^{3}$

The dramatic changes in global food prices, with rice prices reaching an unprecedented $\$ 1,000 /$ ton on the week of the conference in April 2008, have brought food provision to the forefront of public health concern. The effect is felt the most in areas least able to cope with the problem. In sub-Saharan Africa, a consequential rise in child undernutrition is anticipated, and although unlikely to face starvation, South-East Asian countries will suffer severe economic difficulties following reduced rice exportation. As gross domestic product (GDP) falls mortality rises, and the long-term impact on this region must not be underestimated. ${ }^{4}$

Daniela Kirwan, Foundation Year 2 Doctor, Ealing Hospital, London

This conference was held at the Royal College of Physicians on 29 April 2008 and was organised by Dr Michael Pelly, Associate International Director, Royal College of Physicians
Increasing population densities have led to increased contact between humans and livestock, facilitating the evolution and transmission of zoonotic infections. Furthermore, the exponential increase in travel over the last four generations has huge implications for infectious diseases. Over 4.5 billion individual air journeys are made every year, and each has the potential to carry disease. The global aviation network map indicates that the largest and most interesting change is occurring over China; the problems of a rural Chinese village have become the problems of the world.

The severe acute respiratory syndrome (SARS) outbreak in 2003 alerted the world to the inadequate international notification mechanisms. This zoonotic infection began in a rural Chinese province, spread swiftly to Hong Kong, and within a week had infected 8,000 people worldwide. Analysts found that there had been a series of delays in reporting the outbreak, allowing it to gain a foothold. The International Health Regulations (IHR) mechanism for disease notification dated back to 1969 and focused on the main infectious threats of the time: cholera, plague, and yellow fever. SARS led to the realisation that a new, more relevant, formal network for alerting and communicating between countries was needed.

The World Health Assembly passed a resolution in 2005 to 'prevent, protect against, control and provide a public health response to the international spread of disease', and to do this 'in ways that are commensurate with and restricted to public health risks, and which avoid unnecessary interface with international traffic and trade'. The new regulations affirmed each country's duty to participate in global surveillance. National IHR focal points must now notify all potential international public health emergencies and respond to requests for verification of reports within 24 hours, and disclose suspected risks in other areas.

During the SARS response, the World Health Organization (WHO) used a pre-existing laboratory network with impressive results: within six weeks, the pathogen had been isolated and its genome sequenced. This was an astounding response, but did not lead to the termination of the epidemic, which thankfully burnt out by itself. We were lucky. WHO has now developed an Integrated Capacity Development for Laboratory Specialists, with a vision of the earliest possible detection of epidemic threats through a network of effective diagnostic laboratories. A training programme based on world regions aims to support areas with a poor laboratory network, in order to achieve a sustainable improvement in laboratory infrastructure.

Despite these recent efforts, however, current pandemic plans remain somewhat lacking in detail. In the context of increased travel, new epidemics require increasingly sophisticated information capture, yet potential powerful statistical tools are largely underutilised in medicine. This is the focus of research at Imperial College London using mobile telephones to track 


\section{Conference programme}

\section{CURRENT PRIORITIES IN GLOBAL HEALTH}

Keynote talk - Global health: epidemiology and public health challenges Professor Sir Roy Anderson FRS, Chair in Infectious Disease Epidemiology and Rector Elect, Imperial College London

\section{RESPONDING TO GLOBAL HEALTH CHALLENGES: COMMUNICABLE DISEASES}

The International Health Regulations and global alerting Professor Peter Borriello, Director, Centre for Infections, Health Protection Agency

3 by 5 success or failure? Professor Brian Gazzard, Research Director, HIV/GUM Unit, Chelsea and Westminster Hospital, London

The rise of MDR and XDR-TB and the collision with HIV Dr Paul Nunn, Coordinator, TB/HIV and Drug Resistance, World Health Organization

\section{RESPONDING TO GLOBAL HEALTH CHALLENGES: CHRONIC DISEASES}

The global epidemic of obesity, diabetes and cardiovascular disease Dr Shanthi Mendis, Senior Adviser, Cardiovascular Disease, World Health Organization Opium, tobacco, and alcohol: the evolving legitimacy of international action Professor Martin McKee CBE, Professor of European Public Health, London School of Hygiene and Tropical Medicine

Guest lecture - Health security: foreign policy and global health The Rt Hon Lord Malloch-Brown, Minister for Africa, Asia and the UN

\section{GLOBALISATION AND HEALTH: CHALLENGES}

Intellectual property, access to medicines and health tourism Professor Rifat Atun, Director, Centre for Health Management, Imperial College London

Challenges for health systems: migration, permits and visas Professor James Buchan, Health Sciences, Queen Margaret University, Edinburgh

Conflict: public health challenges Dr Mary Black International Adviser, Royal College of Physicians Climate change: public health challenges Dr Maria Neira, Director, Department of Public Health and Environment, World Health Organization

\section{GLOBALISATION AND HEALTH: THE UK RESPONSE}

The UK's Global Health Strategy Dr Nick Banatvala, Head of Global Health, Department of Health

The Prime Minister's Global Health Partnership Initiative Louisiana Lush, Department for International Development Improving health systems: a plan of action for practical collaboration at every level Carolyn Miller, Chief Executive, Merlin

\section{HEALTH LINKS BETWEEN THE UK AND DEVELOPING COUNTRIES}

Dr Andrew Purkis OBE, Chief Executive, Tropical Health and Education Trust

Dr Douglas Lungu, Director, Daeyang Luke Hospital, Malawi and Tropical Health and Education Trust Health Links Coordinator in Malawi population movements. This is expected to give accurate predictions on progression of epidemics, and inform on timescales and the effectiveness of key interventions, such as closing borders. Perhaps the most significant infective threat today is the influenza A virus. Unlike SARS, infection is often asymptomatic leading to late detection, and viral shedding occurs too early within its lifecycle for quarantine to be effective.

The sixth Millennium Development Goal pledges to 'combat HIV/AIDS, malaria and other diseases'. Tropical diseases have historically been neglected, despite affecting large numbers of people and being relatively cheap to treat. Professor Sir Roy Anderson asserted that $\$ 250$ million per year spent on these 'other diseases' could significantly reduce their impact. International policy makers are increasingly realising the huge health benefits of intervention in this area.

In 2006 the Global Network for Neglected Tropical Diseases was formed and implemented provision of a rapid impact package, a basket of drugs including three anthelmintics and the antibacterial azithromycin to treat seven neglected diseases. ${ }^{5}$ Benefits are evident: an immediate increase in child growth rate and educational attainment.

Despite devotion of much attention and resources to HIV, the pandemic continues to affect individuals and families and is profoundly undermining the struggle of heavily burdened states towards development. A number of preventative measures have proved disappointingly ineffective, including microbicides and vaccines, both found to increase the risk of infection. Neither is there convincing evidence of an effect of the promotion of the $\mathrm{ABC}$ policy (Abstinence, Be faithful, use a Condom).

Effective preventative measures do exist. There is strong evidence supporting male circumcision, including a Kenyan randomised controlled trial that showed a cumulative HIV incidence of $2.1 \%$ in circumcised men compared to $4.2 \%$ in controls, or a protective effect of $60 \% .{ }^{6}$ Despite this, male circumcision is little used. In March 2007, experts from WHO and UNAIDS recommended that male circumcision now be recognised as an additional important intervention to reduce the risk of heterosexually acquired HIV infection in men, as part of a comprehensive package. ${ }^{7}$ Further research is needed in this field: the effect of circumcision on sexual behaviour, its effect on women, or its effect on men who have sex with men is not yet understood.

The best way to combat the HIV/AIDS epidemic is undoubtedly through treatment. The ' 3 by 5 ' initiative was a pledge to provide 3 million people with antiretroviral therapy by 2005 . The coverage achieved was 1.3 million, falling markedly short of the target. ${ }^{8}$ Furthermore, provision has been skewed towards the wealthier regions of the world, with sub-Saharan Africa shouldering $76 \%$ of the total unmet need among adults in $2005 .{ }^{9}$ However, some countries have made a dramatic effort and achieved good results, including Botswana which achieved 85\% coverage.

At the 2005 UN World Summit, world leaders pledged to strive for universal access to antiretrovirals by 2010, and countries and organisations are scaling up their efforts to this end. However, the 
lack of country-specific targets and WHO workers on the ground remain barriers. The biggest challenge is patient adherence to medication, but behavioural change is difficult to achieve and does not respond well to education or scientific trial conditions.

With HIV, individual countries make the difference between success and failure. Brazil, Thailand, and Uganda particularly can be held up as success stories. In order to support national efforts, the international community needs to foster empowerment rather than paternalism, facilitate rather than direct, promote true 'equal value' commitment rather than imposition of Western values, and ensure sustainability of all policy and provision.

The decline in tuberculosis (TB) in Britain in the last two centuries led to a degree of complacency. However, TB is not yet beaten, and indeed we are seeing increasing rates of multi-drug resistant (MDR) TB and a worrying surge in extensively-drug resistant (XDR) TB. This not only affects the developing world but also increasingly the UK as a result of globalisation. The enormity of this problem must not be underestimated. Drug resistance arises by selection of naturally occurring mutations through sub-lethal concentrations of drugs. This occurs due to failure of health systems, health policies, drug manufacturers, prescribers, patient adherence, or a combination.

WHO estimates that in 2006 there were 9.15 million new cases of TB, including approximately 489,000 cases of MDR-TB, 40,000 of XDR-TB, 700,000 of HIV-associated TB, and 1.65 million deaths. MDR-TB is increasing in new cases, particularly in the former Soviet Union, implying active circulation within communities. XDR-TB had been confirmed in 46 countries by February 2008. As both infections deplete CD4+ immune cells, HIV and TB co-infection speeds progression of both diseases. HIV prevalence in new TB cases is worst in areas where HIV is prevalent, such as sub-Saharan Africa, and where HIV is rising the fastest, such as the former Soviet Union.

In 2006 the Lancet reported a study in Tugela Ferry, South Africa. ${ }^{10}$ Of 544 culture positive TB patients, 221 had MDR-TB and 53 XDR-TB. Twenty-six of the XDR-TB patients had not been previously treated, and all 44 who were tested for HIV were positive. Of the $53 \mathrm{XDR}-\mathrm{TB}$ patients, 52 were dead within an average of 25 days of testing. These shocking findings were confined to one location with unique characteristics, but the conditions that gave rise to this are found elsewhere, and increasing linkage is being seen between HIV and TB resistance, particularly in the former Soviet Union.

What has been achieved so far? Since the implementation of the DOTS strategy in 1995 there has been a global rate of $61 \%$ case detection and $84.7 \%$ treatment success, not far from the targets of $70 \%$ and $85 \%$ respectively. Between 1995 and 2006, 31.8 million TB cases were notified and treated under DOTS. But only 12,000 MDR-TB patients receive quality-assured treatment every year, just $2.4 \%$ of the global need.

National and international leadership and coordination, and partnerships with community activists and patients, are essential. Resistant strains are much more complex, difficult to manage, and expensive to treat. HIV co-infection is likely to be causing small outbreaks, which go unnoticed in Africa and unreported in Eastern Europe, with very high fatality.

More effective basic TB management and expansion of management of MDR- and XDR-TB are needed. Infection control measures are dire in most health facilities in the developing world, and must be improved. There is a need to strengthen laboratory services to detect cases more effectively, and expand surveillance of resistant strains. The front cover of the Lancet reported in 2006 that 'failure to act now to contain the threat posed by XDR-TB will have devastating consequences for patients with TB, particularly those co-infected with HIV/AIDS'; this applies now as it did then.

\section{Non-communicable diseases}

Shifting demographics and development are resulting in an alarming increase in morbidity and mortality from noncommunicable disease, particularly cardiovascular disease, diabetes, and obesity. This growing burden is an impediment to poverty alleviation and economic growth and impacts unfairly on families and individuals.

WHO has projected that the numbers of overweight and obese adults will almost double from 2005 to 2015. Thirty per cent of global mortality is attributable to cardiovascular diseases, amounting to 17 million deaths per year. Three quarters of this burden falls on low- and middle-income countries, and this proportion is rising.

Progression of non-communicable diseases is insidious. Symptomatic disease forms only the tip of the iceberg, with risk factors lurking unrecognised beneath. These include obesity, physical inactivity, poor diet, tobacco use, and poverty, and are driven by globalisation, urbanisation, and ageing. Addressing these risk factors that affect over two billion people requires a twofold approach: population strategies, such as tobacco and salt regulation, and strategies targeting high-risk groups.

Low- and middle-income countries face a complex scenario with limited resources and competing health priorities. The main challenges are providing cost-effective and affordable services and tackling determinants of unhealthy behaviours outside medicine. Opportunities to improve non-communicable disease control arise from increasing global connectivity and lessons learnt from intersectoral collaboration. Services must be balanced with available resources to safeguard equity and social justice. Leadership by the Department of Health (DH) is vital to address health in all government policies, and support of other stakeholders and capacity strengthening through effective partnerships are key to success.

The WHO Global Strategy on Non-communicable Diseases is directed at reducing premature mortality and improving quality of life. ${ }^{11}$ The Action Plan for the Global Strategy aims to consolidate this further, also taking into account strategies on tobacco control, alcohol, diet and physical activity. The global burden of non-communicable diseases continues to grow, and tackling it constitutes one of the major challenges for development in the 21 st century. 
National economies undeniably benefit from international trade. However, economic performance is an extremely narrow measure of progress. Indeed, there are examples where fast, uncontrolled economic growth has led to ill-health, such as the phenomenal rises in diabetes. Moreover, international trade laws do not differentiate the exchange of beneficial 'goods', including fruit, vegetables, or essential drugs, from harmful 'bads', such as weapons, alcohol, and tobacco. Previously, trade in harmful products, notably opium and tobacco, has been used by powerful countries as an instrument of economic development at the expense of others.

There has, however, been an encouraging reversal in roles and policy. In May 2003 WHO enacted the Framework Convention on Tobacco Control (FCTC). This prohibits tobacco advertising and empowers governments to resist pressure from international tobacco companies. Alcohol has provided a similar challenge. Liberal European Union (EU) regulations have resulted in lower alcohol prices that have caused a steep rise in consumption and deaths from alcohol-related causes. Europe's governments have finally recognised the need to act on alcohol, and the European Commission has brought forward proposals to balance international market considerations with those of health.

These measures represent the beginning of a shift from protection to persecution of trade in substances damaging to health. In a globalised world it is entirely legitimate to put in place systems that will maximise the benefits and minimise the harm from international trade. This has already been done with narcotics and promising steps regarding tobacco and alcohol have also been made, but there is still a long way to go.

\section{Foreign policy}

Health has always been a foreign policy issue, and was secured firmly on the global agenda by Dr Gro Harlem Brundtland in a 1999 speech. ${ }^{12}$ Health is a valuable diplomatic tool that can improve international relations. This issue appeals not just to philosophy and altruism but to Britain's own interests: global health is a modern security issue. Bad health ultimately means sick politics. It causes social disorder, loss of markets and inability to integrate into the global economy, and international hostility. By protecting nations against health threats governments can promote internal and global stability.

As it largely affects adults of working age, disease severely hinders economic growth. WHO estimated that a minimum health budget of $\$ 34$ per person per year would save eight million lives and $\$ 360$ billion; although these figures have been widely disputed, the orders of magnitude remain broadly correct. The majority of the ill-health burden can be eased relatively cheaply, and such interventions could significantly alleviate the global economic crisis.

Lord Malloch-Brown, Minister for Africa, Asia and the UN, proposed four key actions. Firstly, prioritisation of cheap interventions that bring rapid improvements in health. The Alma Ata declaration of 1978 underlined the importance of simple public health interventions in improving standards of health in devel- oping countries. Subsequent successful policies have included promotion of rehydration salts and immunisation programmes. Sadly, 30 years on, this message requires reiteration.

Secondly, effective international cooperation is vital. In order to improve collaboration between international agencies, donors, and poor countries, the UK government launched the International Health Partnership (IHP) in 2007. ${ }^{13}$ The IHP intends to direct support to the priorities identified in the national health plans of poor countries. There is little international confidence in the quality of many governmental health plans, and the IHP focuses on strengthening health systems, planning and accountability at a national level. The drive to 'campaign vertically and spend horizontally' aims to attract investment towards national, rather than vertical, programmes.

External aid for health has increased enormously, from an estimated \$6-17 billion between 2000 and 2006. Much of this is delivered via complex and fragmented aid architecture and absorbed by administrative costs. Over 100 global health initiatives exist and resources are delivered through elaborate supply chains. The result is limited reach and effectiveness of aid. Health workers often complain that they spend more time dealing with donors than running their health services; administration consumes $27 \%$ of Zimbabwe's entire health budget. Key within the IHP is the need to ensure a light bureaucratic burden.

Thirdly, the imbalance in global health spending that persists, despite huge mobilisation of resources, must be addressed. This is not just the responsibility of government but also the private sector and civil society, and further integration between these sectors is imperative. Eyes are opening to opportunities in markets in Africa and elsewhere.

Migration of skilled health workers presents the fourth challenge. There is a worldwide shortage of four million health workers. Additionally there has been an increase in mobility of skilled workers as part of the general trend of globalisation, with net movements away from developing countries. This process is dynamic, varying by country and over time, and is affected by changes in policies and labour markets nationally and internationally. This is a complex issue with many actors and no quick solution.

Challenges include providing efficient and ethical recruitment, and equal opportunities in destination countries. Source countries face skills shortages (for example, 75\% of Zimbabwe's qualified doctors have emigrated) and increased workload and impaired morale in workers left behind. However, migration offers opportunities through remittances, improved pay and career prospects for migrants, and a solution to skills shortages in receiving countries. It is possible to shift the overall impact towards such positive effects through international policy. Destination countries should aim for self-sufficiency, and a coordinated approach to harm reduction in recruitment activities.

One of the drivers behind health worker migration has been an increase in active recruitment. The NHS's success is heavily dependent on overseas expertise. The UK produced a code of conduct in its recruitment policies in 2001 to minimise the 
impact on the developing world, and the Department for International Development (DfID) invests heavily to recruit and retain healthcare workers in poor countries. In his 2007 report on Global Health Partnerships, Lord Crisp recommended that the UK should support international efforts to manage migration and mitigate the effects of its policies on developing countries. He placed the NHS in a global context and argued for an NHS framework for international development. An interministerial group was subsequently set up to further develop policy in this area.

WHO is currently developing a global code to be finalised at the 2009 World Health Assembly. This represents a groundswell towards a pan-national approach. The developed world will not be able to maintain future levels of healthcare workers without engaging globally. It needs to ensure that this does not happen in a market-driven way, but accept that there are policies that may influence, regulate and minimise harm.

\section{Globalisation and health: challenges}

Unpopular international laws regulating intellectual property rights and access to medicines have been challenged with some success. This has mainly applied to anti-retroviral medications for HIV/AIDS. The main breakthrough came in 2005 with the amendment of the World Trade Organization agreement TRIPS (Trade-Related Aspects of Intellectual Property Rights). This allowed developing countries to import generic drugs more cheaply. Patients with HIV can now be treated for only $\$ 100 /$ year.

In 2006, compulsory licensing was granted in Thailand for clopidogrel for use in ischaemic heart disease. This shifted the emphasis from communicable to noncommunicable diseases for the first time. This raises difficult questions of boundaries: which countries are poor enough, and which diseases pose enough of a threat?

Health tourism comprises less than $5 \%$ of the global healthcare market, but this is growing at $6 \%$ per year. Thailand received 1 million medical tourists in 2003 and 1.26 million in 2005 , amounting to $\$ 8.6$ billion dollars of income. Drivers include rising international demand, increased information availability, emergence of international accreditation, and growing acceptability. The EU is 'fully committed' to crossborder healthcare and emphasises free movement of individuals, goods, services and capital. Yet there are few studies looking at the impact of health tourism on global health and health systems in developing and developed countries. The international community needs to look further into the implications of this rapidly growing industry and prepare itself accordingly.

Conflict is big money. Globally, $\$ 1.2$ trillion is spent on armaments every year, and the United Nation's total budget is less than $2 \%$ of global military expenditure. Mortality and morbidity from conflict is immense and, with better military hospitals, more disabled soldiers are returning home. The effects are, as usual, felt most in poorer countries, where the quality of rehabilitation and equipment, such as prostheses, is much worse.
Nations in conflict have some of the worst health indicators, and violence places pressure on health systems that consistently fail to reach their full potential. ${ }^{14}$ It causes displacement of large populations into overcrowded temporary settlements. This leads to increased exposure to disease vectors and inadequate sanitation and safe water. Longer-term effects include poor nutrition, disruption of health infrastructure, staffing difficulties, and chronic lack of investment into health and public facilities. The cycle of destruction and rebuilding of healthcare facilities is demoralising, and accurate data collection is near-impossible.

The vicious spiral of violent conflict and poor health affects us all. Healthcare workers cannot remain neutral and must engage in these issues. They have an important role in mitigating the effects of conflict through advocacy, promoting human rights, and tackling global health challenges.

Likewise, the impact of a changing climate on health is felt by everyone, from victims of a Burmese cyclone to Shropshire families affected by flooding. Warnings from the scientific community have fallen largely on deaf ears. Recently, however, there has been accelerating political interest, with a rush of recent international commitments and targets.

There is strengthening evidence that human activity is causing changing patterns of rainfall, increasing natural disasters, and a global temperature rise. There is a clear association between climate change and deaths; the 2003 heat wave in Western Europe saw an estimated excess of over 70,000 deaths as a direct result. Furthermore, floods, droughts and storms cause vulnerability of populations to vector-borne infections and exposure to toxic substances. On a more far-reaching scale, they cause mental health effects, destroy health services, affect food production, and increase water scarcity. The poorest populations are the least responsible, but most vulnerable.

The health sector has a responsibility to lead by example. International public health workers can use evidence to raise awareness, and put health at the heart of climate change debate. Public health systems must be strengthened to cope with this additional burden, surveillance and response improved, and sustainability within the health sector achieved. WHO has good initiatives in place including guidance on reducing levels of emissions. The importance of research must not be overlooked. Evaluation of the effectiveness of interventions is necessary to ensure we are engaging in the right direction. Climate change certainly presents a great challenge but there are some opportunities for engagement.

\section{Globalisation and health: the UK response}

Sir Liam Donaldson's 2007 report recognised that:

$\ldots$ if the UK is to protect the health of its population, harness the benefits of globalisation and maximise its contribution to international health and development, it needs to have a clear, coherent and coordinated approach to the many issues that influence global health. ${ }^{2}$

The strategy aims to encourage coherence and consistency in government policy that affects global health, and provide a 
mechanism for holding the government to account. It incorporates the many existing government documents with relevance to health and is an evolving process of public debate and consultation. ${ }^{15-19}$ The strategy emphasises the links between health and foreign policy and identifies areas for action. These include: global health security, systems for delivering health, international health architecture, the links between health and trade, and the importance of investment in research and new technology. There is ongoing debate regarding how best to deliver healthcare. Strengthening of health systems, tackling the global workforce crisis, and cost-effectiveness are aspirations that are easy to utter but incredibly complex to deliver. The DH has acknowledged a need to clarify and, where necessary, strengthen the role and responsibilities of different agencies in the UK if the effectiveness of partnerships are to be maximised.

In response to the Crisp Report, the DH has laid out financial and political support for plans to improve the ease with which health professionals are able to contribute to global health. ${ }^{20} \mathrm{~A}$ UK International Health Links Centre will facilitate developing and maintaining links between institutions in the UK and abroad. Additionally, it will promote and disseminate best practice, and maintain a database of UK organisations willing to act as a resource for overseas countries. $\mathfrak{£} 1.25$ million per year has been set aside for this scheme, which will be independently evaluated in order to ensure wise investment. In addition, there is a public sector pension's pilot of $£ 13$ million over three years to support individuals choosing to work in global health.

Long-term partnerships between UK institutions and developing countries can strengthen basic health services and medical education. It is on this basis that the Tropical Health and Education Trust (THET) was founded in 1988. Fundamental principles of good health links are sustainability and responsiveness to priorities identified by the overseas partner.

Dr Douglas Lungu, Director of Daeyang Luke Hospital, Malawi, gave an inspiring account of his experiences as part of a Links project. He described the difficulties that he had previously encountered with non-governmental organizations (NGOs), including hidden costs that can often make simple interventions unfeasible, and the benefits that have arisen in his hospital since forming a link. Unlike most NGOs, health links are a lifeline of stable support that is long term and shielded from political shocks. Links not only provide finances, support, and education, but also friendship and lasting relationships. Benefits extend both ways leading to mutual inspiration and development.

British organisations, such as Merlin, are widely respected overseas and have contributed significantly to health service provision in developing countries. The contribution from independent NGOs can be increased in value by working in partnership with each other. However, intersectoral collaboration can be problematic. Different actors may have competing policy processes and priorities. It is often difficult to find supportive staff and there is little continuity. Engaging parties involved at different levels is challenging, and it is important to cater for the multiplicity of players and adopt a practical and flexible approach. The paucity of reliable data on global health subjects is another problem. Ultimately, research and its implementation will change practice, and such research merits encouragement and funding.

The UK has historically made a valuable contribution to global health. However, this is currently threatened by inflexibility and uncertainties in postgraduate training that have resulted in a climate of fear, real and perceived, that a sabbatical can be detrimental to careers in the NHS. The recent changes in medical training provide an opportunity for a strong and coherent structure that fully supports motivated health professionals to fulfil their aspirations to contribute to global health. Although postgraduate deaneries make provisions for 'out of programme experience', this process lacks guidelines, transparency, and an appeal structure, leading to inconsistency across regions. This presents a significant barrier to individuals wishing to undertake training or research overseas. There is a disappointing dissuasion of non-conventional careers, including those incorporating global health. The $\mathrm{DH}$ needs to ensure that this is rectified.

The boundaries between domestic and foreign agendas are becoming ever more blurred, and health concerns mix increasingly with high politics. It must be recognised that global problems cannot be solved without global solutions. Health can improve global security and enhance human rights, development and trade.

The attendance at this and other similar events, quantity of publications on global health-related topics, and uptake of the growing number of courses on international health indicate the rising recognition of the importance of the issues discussed above. The numerous recent documents relating to global health demonstrate an unprecedented level of political will from the government. Key players must ensure that this enthusiasm translates into commitment and tangible results.

The Royal College of Physicians (RCP) must use its influence to ensure that global health remains prominent on the international policy making agenda. It has an important role in engaging other bodies, such as the deaneries and $\mathrm{DH}$, and advocating inclusion of global health in undergraduate and postgraduate training. This interesting time of evolving training structures within the NHS offers an opportunity for defining the UK's role in global health.

The RCP would like to invite readers to contribute to this ongoing debate. Please send your comments to: Dr Michael Pelly, Associate Director for Global Health or Matthew Foster, Head of International Affairs, at international@rcplondon.ac.uk

\section{References}

1 Crisp N. Global health partnerships: the UK contribution to health in developing countries. London: Department of Health, 2007.

2 Donaldson L. Health is global: proposals for a UK Government-wide strategy. London: Department of Health, 2007.

3 Zimbabwe. The Human Development Index - going beyond income. Human Development Reports, 2007 http://hdrstats.undp.org/countries/ country_fact_sheets/cty_fs_ZWE.html 
4 Dorling D, Mitchell R, Pearce J. The global impact of income inequality on health by age: an observational study. BMJ 2007;335:873.

5 Hortez J, Molyneux DH, Fenwick A et al. Incorporating a rapidimpact package for neglected tropical diseases with programs for HIV/AIDS, tuberculosis, and malaria. A comprehensive pro-poor health policy and strategy for the developing world. PLoS Med. 2006;3:e102.

6 Bailey RC, Moses S, Parker CB et al. Male circumcision for HIV prevention in young men in Kisumu, Kenya: a randomised controlled trial. Lancet 2007;369:643-56.

7 Press release: WHO and UNAIDS announce recommendations from expert meeting on male circumcision for HIV prevention. World Health Organization, 28 March 2007. http://data.unaids.org/pub/ PressRelease/2007/20070328_pr_mc_recommendations_en.pdf

8 Carter M. Final report on 3 by 5 - target not met, but progress and valuable lessons for universal access by 2010. Aidsmap News 28 March 2006. www.aidsmap.com/en/news/B9059B57-61D8-485AA2F7-FB3CC56FAB61.asp

9 Progress on global access to HIV antiretroviral therapy. An update on ' 3 by 5'. World Health Organization, 2005.

10 Gandhi NR, Moll A, Sturm AW et al. Extensively drug-resistant tuberculosis as a cause of death in patients co-infected with tuberculosis and HIV in a rural area of South Africa. Lancet 2006;368:1575-80.

11 World Health Organization. Global strategy for the prevention and control of noncommunicable diseases, 1999. http://ftp.who.int/gb/ archive/pdf_files/EB105/ee42.pdf
12 Brundtland GH. Why investing in global health is good politics. Delivered at: Council on Foreign Relations, New York, 6 December 1999.

13 Department for International Relations. The International Health Partnership launched today, 5 September 2007. www.dfid.gov.uk/ news/files/ihp/default.asp

14 Singh S, Orbinski JJ, Mills EJ. Conflict and health: a paradigm shift in global health and human rights. Confl Health 2007;1:1.

15 Department for International Development. Eliminating world poverty: a challenge for the 21st century. White paper on international development. London: DfID, 1997.

16 Department for International Development. Eliminating world poverty: making globalisation work for the poor. White paper on international development. London: DfID, 2000.

17 Department for International Development. Eliminating world poverty: making governance work for the poor. White paper on international development. London: DfID, 2006.

18 Foreign and Commonwealth Office. Better world, better Britain. London: FCO, 2007. www.fco.gov.uk/en/fco-in-action/strategy

19 Department for International Development. Increasing access to essential medicines in the developing world: UK government policy and plans. London: DfID, 2004.

20 Department of Health. Global health partnerships: the UK contribution to health in developing countries - the Government response. London: DH, 2008.

Email for correspondence: dannikirwan@yahoo.com

\section{NCC-CC GUIDELINES}

\section{Tuberculosis}

\section{Clinical diagnosis and management of tuberculosis, and measures for its prevention and control}

This guideline replaces the British

Thoracic Society 1998 guideline and the

2000 code of practice

The guideline:

- provides full details of systematic reviews of the TB evidence base, health economic modelling, and the considerations from the Guideline Development Group

- provides complete TB best practice guidance for the first time since the switch to intradermal $\mathrm{BCG}$, the adoption of Mantoux rather than Heaf testing, the scrapping of the school vaccination programme and the piloting of pre-entry chest X-ray screening for UK visa applicants

- is the only document to include the full analyses which informed the new policy for targeted neonatal BCG, the adoption of interferon-gamma testing as a second step after skin testing, and focussed new entrant screening over the age of 16

- provides selected recommendations as key priorities for implementation, algorithms for everyday practice use, and suggests topics for clinical audit as well as future research priorities.

The guideline is intended to inform the practice of respiratory physicians, infectious disease physicians, genitourinary physicians, TB and respiratory specialist nurses, consultants in communicable disease control and health protection, infection control nurses, prison medical service staff and nurses involved in refugee induction centres or specialised new entrant services.
Royal College of Physicians setting higher modicat standatds

The National Collaborating Centre for Chronic Conditions

This guideline is part of a series commissioned by NICE which aims to ensure that standards of care throughout England and Wales are uniformly high.

Developed by the National Collaborating Centre for Chronic Conditions at the Royal College of Physicians

Published APRIL 2006

ISBN: 978-1-86016-277-0

Price: $£ 20.00$ UK, £22.00 overseas (prices include postage and packing)

Please quote the reference Clinical Medicine when placing your order 